\title{
Pregnancy and Klippel-Trenaunay Syndrome-A Case Report
}

\author{
María Jesús Cancelo Hidalgo, Gisselle Adriana González Segura, Laura Yago Lisbona, \\ Estherde la Viuda García \\ Department of Obstetrics and Gynecology, University Hospital of Guadalajara, Alcalá University, Madrid, Spain \\ Email: mariajesus.cancelo@gmail.com
}

Received 10 May 2014; revised 9 June 2014; accepted 8 July 2014

Copyright (C) 2014 by authors and Scientific Research Publishing Inc.

This work is licensed under the Creative Commons Attribution International License (CC BY).

http://creativecommons.org/licenses/by/4.0/

\section{(c) (i) Open Access}

\begin{abstract}
Klippel-Trenaunay Syndrome (KTS) is a rare triad of congenital vascular malformations involving extensive Port wine stains, soft tissue or bone hypertrophy and underlying venous and/or lymphatic malformation affecting limb, pelvicor abdominal organs. Pregnancy is known to exacerbate KTS complications and can put women at increased obstetrical risk due to deep venous thrombosis and other thromboembolic events. We report a case of a pregnant woman with KTS with the personal antecedent of two episodes of pulmonary thromboembolism.
\end{abstract}

\section{Keywords}

Klippel-Trenaunay Syndrome, Pregnancy

\section{Introduction}

Klippel-Trenaunay syndrome (KTS) is a multifaceted disorder which can manifest in a number of different ways. It is characterized by conglomeration of capillary malformations, cutaneous vascular nevi, bony or soft tissue hypertrophy, and abnormal deep or superficial veins. Varicose veins usually affect limbs but sometimes they can also be present in abdominal or intrapelvic organs. The morbility of this disease is related to vascular anomalies, which can end in venous insufficiency, thrombophlebitis, cellulite, limb disparity and thromboembolic disease.

The KTS occurs sporadically although it has sometimes appeared in more than one member of the same family. KTS incidence during pregnancy is unknown but it is extremely rare. Pregnancy can increase complications, mainly thromboembolic and haemorrhagic events.

We present a case of a pregnant woman with diagnosis of KTS complicated by the personal antecedents of two episodes of pulmonary thromboembolism.

\section{Clinical Case}

We reported the case of a 31-year-old primigravid woman who has suffered from SKT since her childhood. 
She suffers from SKT, with affection of left leg (Figure 1) and a mild-moderate mitral regurgitation that has not required treatment.

Also, she has had two episodes of pulmonary thromboembolism (PTE) six and two years ago. After the first PTE, she was prescribed anticoagulant therapy for six months. Two years after the suspension of the therapy, a new PTE occurred. So, she was prescribed anticoagulant therapy indefinitely.

She does not have any drug allergies and has not had any previous surgery. Regarding her gynecological history, she had menarche at 13 , with a regular menstrual cycle.

Preconceptional counseling was made. Thrombophilia study was performed but the results were normal. During the pregnancy, ultrasound and analytic tests were normal. Colour Doppler flow was normal in the fetus. There was only one complication: the swelling of her right leg. It was treated with a permanent elastic compression stocking. Hypotension and loss of consciousness happens when the patient retires the elastic compression while she is standing up. She has to cleanse herself in a seated position.

She was on treatment with sodic bemiparine 20,000 UI/24hours until week 35 of gestational age. At this moment, the dose was lowered to sodic bemiparine $10.000 \mathrm{UI} / 24$ hours.

At Week 39 of gestational age, elective cesarean was made because of fetal malposition. A male baby was born; he weighed 2980 gr., Apgar test: 8 and 9 after 1 and 5 minutes. Epidural anesthetic did not cause any complications.

During the surgery, there were not any complication and we did not observe any intra abdominal vascular malformation.

There were no problems in the postpartum period and the different types of tests done gave a normal result. The patient was treated with sodic bemiparine $10.000 \mathrm{UI} / 24$ hours.

Six months later, complications have not been observed. She uses condoms for contraception.

\section{Discussion}

Klippel-Trenaunay syndrome is a congenital vascular disorder which has low frequency $(<1: 10.000)$ [1]. In about $1 \%$ of cases of KTS, a genetic pattern has been described, but the gene has not yet been identified [2].

The presence of this disease can cause severe varicose capillary malformations in other members of the same family. In some cases, KTS is associated with the presence of hemangiomas in the patient's family.

KTS is characterized by conglomeration of capillary malformations, cutaneous vascular nevi, bony or soft

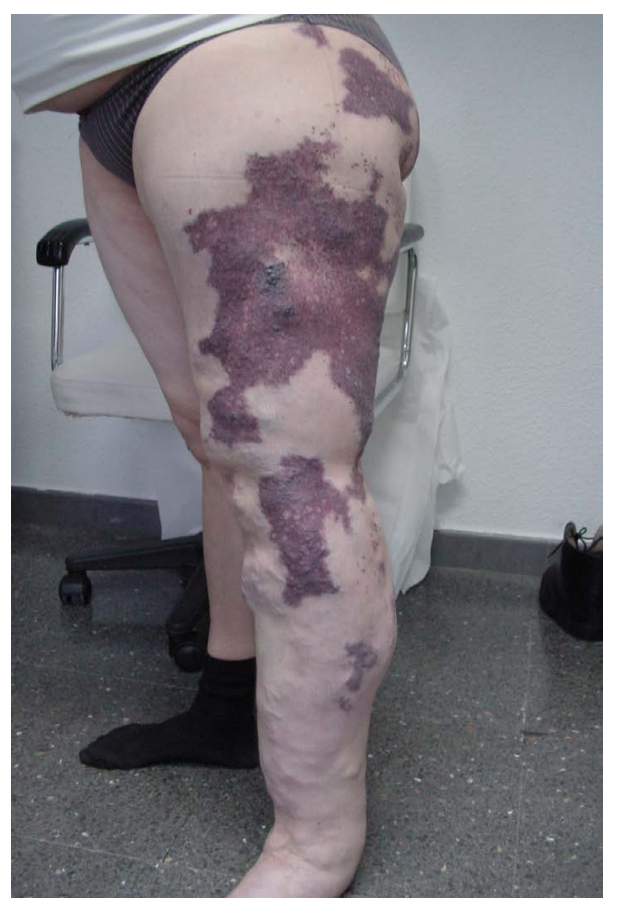

Figure 1. Affection of left leg. 
tissue hypertrophy, and abnormal deep or superficial veins. At least two over three main symptoms (Portwinestains, varicosity, and hypertrophy of soft tissues and bones) must be present for the diagnosis KTS.

The morbidity of the disease is associated with vascular anomalies. This is related to rectal haemorrhage, haematuria or perioperative bleeding in surgeries that compromise intra-abdominal organs [3]. Furthermore anesthetic management in these cases can be rather complicated [4].

The first case was described by Maurice Klippel and Paul Trenaunay in 1900 [5]. They called the disease naevus vasculosus osteohypertrophicus. The diagnostic criteria are capillary malformations, venous malformations and/or varicosities, and hypertrophy of the bone or soft tissues in one or more extremity. Later, Frederick Parkes Weber reported other cases with the same clinical findings associated with deep arteriorvenous fistula.

These cases are referred to as Klippel-Trenaunay-Weber syndrome. Today, KTS is defined by the presence of a combined vascular malformation of the capillaries, veins, and lymphatics with congenital venous abnormalities and limb hypertrophy. It is distinguished from Weber syndrome in which an arteriovenous malformation with a cutaneous capillary malformation and skeletal or soft tissue hypertrophy occurs.

Klippel-Trenaunay syndrome is a pure low flow condition, while Parkes Weber syndrome is characterized by significant arteriovenous fistulas [6].

The etiology of the syndrome is unknown. Several theories have been proposed including abnormalities of the sympathic nerve system resulting in dilatation of the arteriovenous anastomosis or obstruction of the deep veins and persistence of fetal microscopic small arterioveneous anastomosis [7].

KTS is extremely rare in pregnant women and about twenty cases have been described. It puts a pregnant woman at increased obstetric risk and can increase complications, mainly thromboembolic and haemorrhagic events [8].

KTS is a high risk obstetric situation and we have to be aware of maternal and fetal complications. Also, we have to choose the best way of delivery and intrapartum analgesia [9]. The normal physiologic changes of pregnancy, such as increased venous pressure, leg edema, venous stasis, and cardiac output, exacerbate the problems of this syndrome and increase the risk of adverse events during pregnancy such as thromboembolism and haemorrhage [10]. Colour Doppler flow can display eventual uterine affectation, possibly complicating caesarean.

Coagulopathy is the most frequently reported complication during pregnancy in women with KTS, including deep venous thrombosis and other tromboembolic problems both during and after delivery. It is considered that the risk is 10 times higher than in the normal population. In spite of this, there are no prospective trials on the use of anticoagulants and during pregnancy in this syndrome.

If the patient had a thromboembolic even in the past, as in the presented case, the use of anticoagulants agents is indicated [11].

Different reports on prenatal diagnosis of KTS in fetuses have been published [12]. The fetus should be checked for prenatal diagnosis of limb hypertrophy or multiloculated cystic lesions, which can be easily performed by colour Doppler flow [13]. Sometimes this syndrome has been related to intrauterine growth restriction [14]. Although this syndrome is considered a sporadic disease, some hereditary cases may occur.

A gynaecological examination should be made before choosing the best way of delivering in order to discard the presence of varicose veins in uterine cervix or vaginal wall, which could contraindicate vaginal delivery. Except for this, the delivery way is chosen according to obstetric characteristics. Cesarean section can lead to further complications due to the existence of varicose uterine or abdominal wall [15].

Epidural anaesthetic is the best option during labor. The presence of neuraxial vascular anomalies and coagulopathy can increase the risk of epidural hematoma. Some authors avoid epidural anaesthetic in these patients because of the high risk of epidural hematoma, but others recommend serial studies of hemostasis and a magnetic resonance prior to delivery to detect angiodysplastic vascular structures next to the spinal cord [16].

The management of these patients needs a multidisciplinary approach between gynecologist, anesthesiologist, hematologist and vascular surgeon. Thoughtful preconceptional counseling, along with methodical and systematic intrapartum and postpartum care are keys to reducing mortality and morbidity.

\section{References}

[1] Sreekar, H., Dawre, S., Petkar, K.S., Shetty, R.B., Lamba, S., Naik, S. and Gupta, A.K. (2013) Diverse Manifestations and Management Options in Klippel-Trenaunay Syndrome: A Single Centre 10-Year Experience. Journal of Plastic Surgery and Hand Surgery, 47, 303-307.

[2] Hofer, T., Frank, J. and Itin, P.H. (2005) Klippel-Trenaunay Syndrome in a Monozygotic Male Twin: Supportive Evi- 
dence for the Concept of Paradominant Inheritance. European Journal of Dermatology, 15, 341-343.

[3] Herman, R., Kunisaki, S., Molitor, M., Gadepalli, S., Dillman, J.R. and Geiger, J. (2012) Rectal Bleeding, Deep Venous Thrombosis, and Coagulopathy in a Patient with Klippel-Trénaunay Syndrome. Journal of Pediatric Surgery, 47, 598-600. http://dx.doi.org/10.1016/j.jpedsurg.2011.12.016

[4] Barbara, D.W. and Wilson, J.L. (2011) Anesthesia for Surgery Related to Klippel-Trenaunay Syndrome: A Review of 136 Anesthetics. Anesthesia Analgesia, 113, 98-102. http://dx.doi.org/10.1213/ANE.0b013e31821a03c2

[5] Klippel, M. and Trenaunay, P. (1900) Naevus Variquenx Osteohypertophique. Archives Générales de Médecine, 3, 641-672.

[6] Ziyeh, S., Spreer, J., Rössler, J., Strecker, R., Hochmuth, A., Schumacher, M. and Klisch, J. (2004) Parkes Weber or Klippel-Trenaunay Syndrome? Non-Invasive Diagnosis with MR Projection Angiography. European Radiology, 14, 2025-2029. http://dx.doi.org/10.1007/s00330-004-2274-8

[7] Gloviczki, P. and Driscoll, D.J. (2007) Klippel-Trenaunay Syndrome: Current Management. Phlebology, 22, $291-298$. http://dx.doi.org/10.1258/026835507782655209

[8] Blasco, M. and Herrera, J. (2012) Klippel-Trenaunay Syndrome Complicating Pregnancy. BMJ Case Reports. http://dx.doi.org/10.1136/bcr-2012-006534

[9] Stein, S.R., Perlow, J.H. and Sawai, S.K. (2006) Klippel-Trenaunay-Type Syndrome in Pregnancy. Obstetrical Gynecological Survey, 61, 194-206. http://dx.doi.org/10.1097/01.ogx.0000201924.87671.90

[10] Torres-Farías, E., Torres-Gómez, L.G. and Burciaga-Sepúlveda, A.S. (2010) Klippel-Trenaunay Syndrome and Pregnancy. Case Report. Ginecologíay Obstetetricia de Mexico, 78, 287-290.

[11] Redondo, P., Aguado, L. and Martínez-Cuesta, A. (2011) Diagnosis and Management of Extensive Vascular Malformations of the Lower Limb: Part II. Systemic Repercussions, Diagnosis, and Treatment. Journal of the American Academy of Dermatology, 65, 909-923. http://dx.doi.org/10.1016/j.jaad.2011.03.009

[12] Peng, H.H., Wang, T.H., Chao, A.S., Chang, Y.L., Shieh, S.C. and Chang, S.D. (2006) Klippel-Trenaunay-Weber Syndrome Involving Fetal Thigh: Prenatal Presentations and Outcomes. Prenatal Diagnosis, 26, 825-830. http://dx.doi.org/10.1002/pd.1512

[13] Chen, C.P., Lin, S.P., Chang, T.Y., Lee, H.C., Hung, H.Y., Lin, H.Y., Huang, J.P. and Wang, W. (2007) Prenatal Sonographic Findings of Klippel-Trénaunay-Weber Syndrome. Journal of Clinical Ultrasound, 35, 409-412. http://dx.doi.org/10.1002/jcu.20323

[14] Fait, G., Daniel, Y., Kupferminc, M.J., Gull, I., Peyser, M.R. and Lessing, J.B. (1996) Klippel-Trénaunay-Weber Syndrome Associated with Fetal Growth Restriction. Human Reproduction, 11, 2544-2545. http://dx.doi.org/10.1093/oxfordjournals.humrep.a019156

[15] Güngor Gündoğan, T. and Jacquemyn, Y. (2010) Klippel-Trenaunay Syndrome and Pregnancy. Obstetrics and Gynecology International, 2010, Article ID: 706850. http://dx.doi.org/10.1155/2010/706850

[16] Lee, J.H., Chung, H.U. and Lee, M.S. (2012) An Anesthetic Management of a Patient with Klippel-Trenaunay Syndrome. Korean Journal of Anesthesiology, 63, 90-91. http://dx.doi.org/10.4097/kjae.2012.63.1.90 
Scientific Research Publishing (SCIRP) is one of the largest Open Access journal publishers. It is currently publishing more than 200 open access, online, peer-reviewed journals covering a wide range of academic disciplines. SCIRP serves the worldwide academic communities and contributes to the progress and application of science with its publication.

Other selected journals from SCIRP are listed as below. Submit your manuscript to us via either submit@scirp.org or Online Submission Portal.
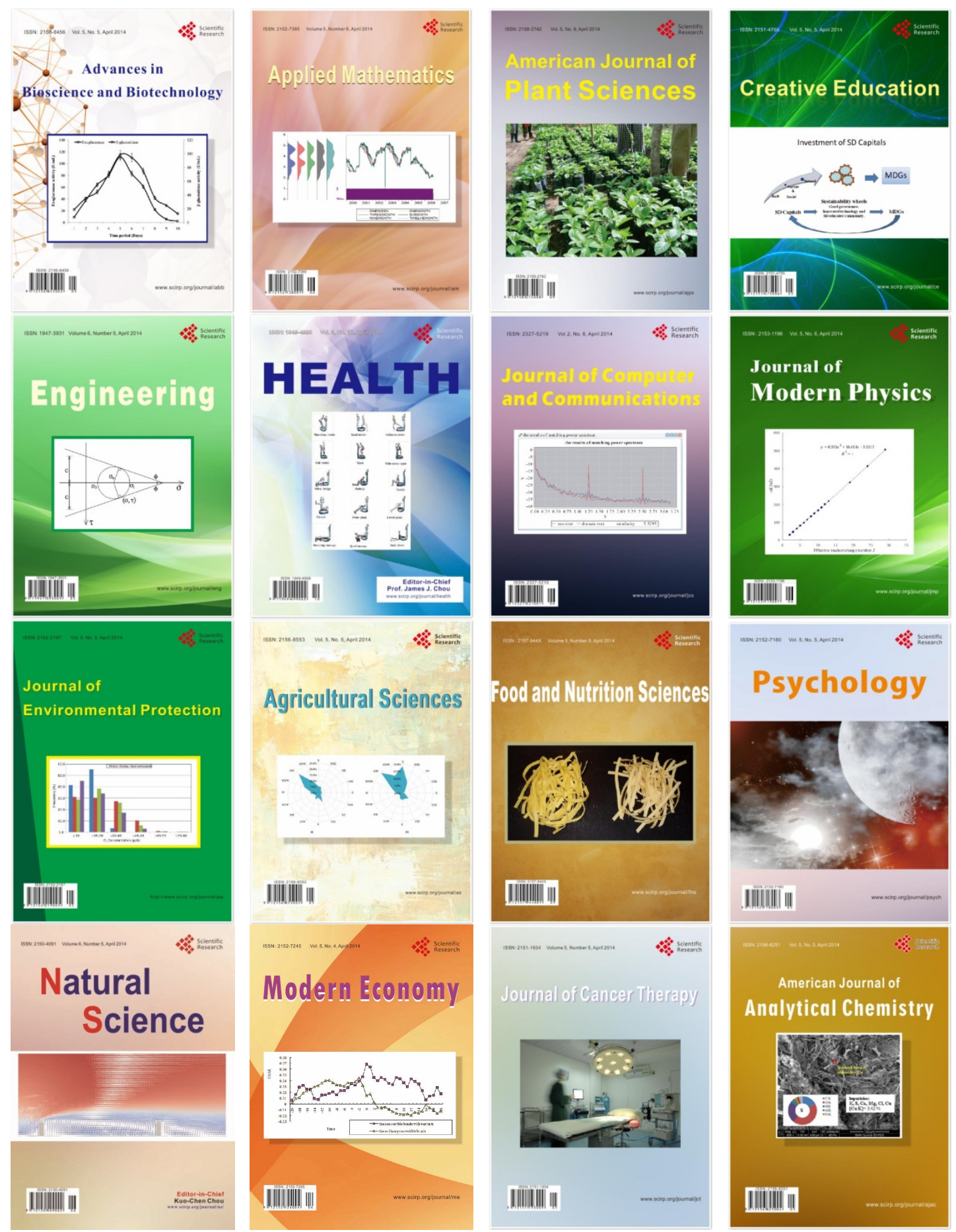